\title{
Impact of Innovative Teaching and Learning Methodologies for Higher Educational Institutions with Reference to Trichirappalli District.
}

\author{
*V.Senthilkumar ${ }^{1}$, Dr. R.Kannappa ${ }^{2}$ \\ ${ }^{1}$ PhD Research Scholar in Commerce Periyar EVR College Trichy. \\ ${ }^{2}$ M.Com., M.B.A.,M.Phil., PhD ., Professor Cum Research Advisor in Commerce, Periyar EVR College Trichy.
}

\begin{abstract}
Absrract: The application of innovative teaching and learning methods is critical if we are to motivate and engender a spirit of learning as well as enthusiasm on the part of students, for learning while at universities and indeed for lifelong learning. The role of education is to ensure that while academic staffs do teach, what is taught should also be intelligible to students emanating from culturally and linguistically diverse backgrounds and that they rapidly become familiar with the expected standards. It is more often than not the case that students underachieve because of the fact that they have not grasped an awareness of the level of assessment or what it is that the lecturer expects from them. Lecturers should thus apply themselves to utilizing innovative methods so that the students' learning process is as free-flowing as possible and that the methodology they adopt is conducive to learning. Innovative teaching and learning methodologies such as Short Lecture, Simulation, Role-Playing, Portfolio Development and Problem-Based Learning (PBL) are very useful in addressing the rapid technological advances and developing workplaces that will be required in the foreseeable future. This article which is important in the broader transformation debate in higher education focuses on skills that can strengthen language acquisition and content knowledge for students. PBL inter alia, is promoted as an innovative teaching and learning methodology that is highly relevant and meaningful and worth utilizing.
\end{abstract}

Keywords: Innovative Teaching and Learning, Short-Lectures, Role-Play, Simulation, Portfolios, ProblemBased Learning.

\section{Introduction}

"Education Is the Manifestation Of Perfection Already In Man" - (Swami Vivekananda) Meaning

Education is a very powerful instrument for social change and transformation and innovative teaching practice is the only way to enhance the quality of our education. The problems which society faces are essentially the problems of educational institutions which are required to be innovative as they teach new skills and develop new insights and approaches towards the solving of social problems which the nation faces. Students must be empowered to be able to withstand the global challenges of the 21 st century.

\section{Definition}

The Oxford Dictionary defines innovation as "the introduction of novelties, the alteration of what is established methods" which is what this article strives to do. A key performance indicator of any education institution is the education quality in especially teaching and learning areas.

\section{Importance}

Education is a light that shows the mankind the right direction to surge. If education fails to inculcate self-discipline and commitment to achieve in the minds of student, it is not their fault. We have to convert education into a sport and learning process has to generate interest in the students and motivate them to stay back in the institution than to run away from it. Education should become a fun and thrill to them rather than burden and boredom. It is an integral part of their growth and helps them become good citizens. Education is an engine for the growth and progress of any society. It not only imparts knowledge, skills and inculcates values, but is also responsible for building human capital which breeds, drives and sets technological innovation and economic growth. In today's era, information and knowledge stand out as very important and critical input for growth and survival. Rather than looking at education simply as a means of achieving social upliftment, the society must view education also as an engine of advancement in an information era propelled by its wheels of knowledge and research leading to development.

Lecturing is a communication between two or more persons who influence each other by their ideas and learn something in the process of their interaction with one another. Lecturing is thus a complex, exciting, challenging and interactive skill whose main aim is to create a learning situation in which knowledge is imparted and in which understanding and skills are developed. Students are motivated to explore the discipline 
they have selected. Unfortunately many students fail to complete their studies at university but may still benefit from skills that are developed while at an institution, especially the confidence they obtain from new life experiences (Quinn et al., 2005). What is required for all students, even those that drop out, is deep rather than surface learning.

There are a number of traits required of the innovative lecturer which include humility, courage, impartiality, open-mindedness, empathy, enthusiasm, judgement and imagination (Hare, 1993). It is these lecturers who will infuse deeper learning in their students. Brockbank and McGill (1998) refer to reflective practice and learning and provide numerous examples of reflection in action by both academic staff and students. The focus must shift from 'talk and chalk' to how students learn and lecturers need to instil a deep approach to learning by giving students varied innovative stimulating learning environments in order to create a deeper learning. Learning should be the result of lecturer motivation and facilitation andthe students' learningfocussed activities in which they are engaged and for which they assume ownership (Biggs, 1999). This is why it is imperative that all lecturers seriously engage in reflective practice and experiment with innovative methods where required. They should strive to use personalised strategies to teach and actively engage learners in course content. Stensaker (2008) argues that in order to achieve quality teaching and learning, greater attention must be paid to teaching and learning practice. It is clear that traditional methodologies of 'talk and chalk' which are teacher centred are not adequate for current students and that effective teaching and learning is not taking place at the desired level (Race, 2003).

High-quality learning outcomes are achievable provided that students assume greater control over their own learning (Boud, 1990). This Nicolaides 621 notion is supported by Falchikov (1995) who maintains that greater student involvement in self-assessment and that of their peers is beneficial to them. Students must be immersed in authentic curriculum contents and tasks that are demanding and relevant to their lives and futures (Crosling et al., 2008). Current status Sadly, many lecturers have adopted conventional method of teaching and learning. The teaching is mainly based on the syllabus and prescribed textbooks. In many lecture rooms, teaching and learning techniques are outdated and theoretical knowledge is still disseminated through the technique of talk and chalk.

Learning is a process which should produce desired changes in the behaviour of students. Consequently, the learning situations utilized in the lecture rooms are important for the understanding of the concepts taught. Learning occurs place when insight is gained, and when the processes are understood, in short when interaction has taken place between the lecturer and the learners and between learners and their peers. Some lecturers still believe that knowledge is transferred to their students, but in reality students learn by doing and this is reinforced by the use of innovative teaching methodologies. However, it seems that when lecturers try to be innovative in the learning environment, many fall short, and students thus often prefer to be assessed in a conventional manner. Innovative methods are thus perceived to be a stumbling block for them. Students complain that some assessments do not in any way measure their real learning and what they are assessed with is irrelevant to the real world of work (McDowell and Sambell, 2003).

It is the task of a lecturer to facilitate learning and to motivate, encourage and mentor students to achieve academically with the use of innovative methods and to generally promote interest in their subject which should go beyond the our walls of a lecturer room. Students need ample opportunity to share ideas with the lecturer as well as with their peers and this becomes difficult if nigh impossible especially with large groups of students in one class. Each discipline undoubtedly has unique challenges as well as advantages and opportunities when it comes to innovative teaching. The development of student learning in higher education in the context of teaching and learning is currently a global cause for concern. The large class sizes have led to an increased movement towards a mainly lecture methodology for teaching which has led to far less interaction between students and lecturers and learning quality is thus compromised (Kezar and Kinzie, 2006).

\section{Objectives Of the Innovative Teaching}

- To develop a detailed and systematic methodology to define the criteria for identifying the best practices (as identified in each partner) and then operate as the frame for the collection and formation of exceptional teaching and learning approaches with the view to provide/collect innovative teaching and learning practices.

- To design and develop a web-based Inventory, which will include a collection and categorization of best practices that can support learning community and where users will be able to find, exchange and adapt innovative teaching and learning practices and exchange ideas and best practices.

- To collect and develop innovative, relevant and multilingual content that will support the proposed approach, which will be described and stored (in the form of learning objects) in the Inventory's repository of content.

- To develop ICT literacy skills and ensure the access to and use of innovative teaching and learning practices by the users under the umbrella of community building. Community building is critical 
component that will enable their success in learning programs by reducing isolation, mentoring success, transforming experiences of exclusion to ones of inclusion, offering encouragement and hope, and fostering group dialogue and peer learning from secondary to higher and adult education communities.

- To carry out a set of pilot sessions with a number of representative user groups (teachers, students, parents, policy makers, adults returning to higher education, learners entering the workplace) in order to enrich/ localize/ adapt content to current needs and evaluate the proposed approach.

- To perform an extended dissemination and validation of the project outcomes in a wide network across Europe, and to circulate effective teaching methods through networking with relevant projects, networks and initiatives.

\section{Problems In Innovative Teaching}

Some of the limiting factors can be summarized as:

$>$ This is a one way transmission of knowledge.

$>$ The knowledge is purely factual.

$>$ Students' feedback and queries are very limited or even non-existent at times.

$>$ Course material is limited to the pre-prepared lectures and text books.

$>$ Insufficient elements of interest and engagement for the learners.

$>$ Applied and real life knowledge is least discussed and focus is purely based theory.

$>$ The system promotes memorizing skills of student and least concerned with the understanding

\section{Innovative Short Lecture Methodology}

An innovative teaching and learning methodology which is not often utilized in hospitality and tourism education is a short lecture introducing a problem solving case study, of say 20 minutes, followed by vigorous debate and discussion on the part of students who are organized into groups and who interrogate the responses of fellow students. Student involvement is essential if learning is to be successful. The lecturer as the facilitator is tasked with guiding and promoting student interaction. In classes where I have utilized such a methodology, students become active team-players and role-players. There does need to be prior knowledge on problemsolving and critical thinking techniques in order for this approach to work. It has been shown that interactive teaching is superior to didactic teaching and that the former greatly improves academic success and promotes the inclusion of students who generally feel like outsiders (Crosling et al., 2008) Students need student-centered and active learning that is associated with experiential, problem based and project based learning. Collaborative learning is desirable and there should be far less reliance on the large lecture format that is followed by most lecturers. In fairness to many academics, the institutions often accept more students than they should so as to obtain greater state funding and the result is huge classes that only large lecture formats can accommodate. Nothing can however replace the vital aspects of staff-student and student interaction. Individual learning is however still very important. Lecturers should also not fail to focus on developing tourism and hospitality students' social skills, especially as they will be working with guests from across the globe. Ethics, social and cross-cultural skills, in the context of the tourism and hospitality professions must assume greater importance in teaching content.

\section{QUALITIES OF A GOOD LECTURE}

$>$ A good lecture should not be too long as to exceed the trainees' attention span (up to 25 minutes).

$>$ A good lecture should address a single theme.

$>$ In a good lecture technical terms are carefully explained.

$>$ Familiar examples and analogies are given.

$>$ A good lecture establishes fluency in technical content.

$>$ A good lecture uses illustrations and examples.

$>$ A good lecture builds on existing knowledge.

$>$ A good lecture employs a variety of approaches.

\section{Simulation and Role-Playing}

In these methodologies, the idea is to create a workplace scenario that students could encounter in real life. Such a method will allow students to develop their social skills which are essential for the tourism and hospitality industries. Role-playing and simulation promote an evaluation and synthesis of the teaching material while practically allowing students to learn something by 'doing something'. The lecturer needs to lay down firm ground rules for student involvement so that the exercise does not become theatrical. It must be emphasized at the outset that it is an opportunity to participate in the learning process and that their participation will increase their sense of belonging, motivation and achievement (Askham, 2004). Simulation of scenarios and interrogation of case studies, involving staff and guests in hotels and other tourism operations, are useful in 
problem-solving and in developing the argumentation and analytic skills students that students require in the world-of-work. Such exercises promote understanding and deep-learning that are the prerequisites for long-term knowledge acquisition (Denbo, 2005). This methodology does require planning by the lecturer who must have clear objectives regarding the learning outcomes. Student preparation may be required for certain simulations and role-playing. Lecturer assessment as well as peer and self-assessment may be used to evaluate student understanding. It is important to note that these techniques allow for greater student self refection while simultaneously also enhancing other areas of the learning process. Lecturer and peer feedback are important in assisting students to develop their problem-solving skills and strategies.

\section{Teacher Preparation}

$>$ Rehearse your presentation in advance of the lesson.

$>$ Anticipate any difficult steps, possible interruptions e.t.c.

$>$ Obtain all materials, tools, equipment, visual and teaching aids in advance and check their useful condition.

$>$ Have all materials within reach and conveniently arranged.

$>$ Time the demonstration NOT to exceed 15 minutes.

$>$ Remove all extraneous materials; check lighting, visibility, student grouping, and proximity to electric, gas and water outlets.

$>$ Plan to use a skill or method to advantage; work from simple to complex, one step at a time.

Presentation

$>$ Make sure all students can see and hear the lesson.

$>$ Be enthusiastic, professional, effective but not dramatic.

$>$ Relax; use any mishaps or humour to YOUR advantage.

$>$ Observe all safety rules and procedures.

$>$ Keep eye-contact with the class; ask and encourage class questions.

$>$ Explain WHY and HOW: use the techniques of SHOW and TELL.

$>$ Use a medial summary to strengthen your explanation.

Precautions

$>$ Avoid interruptions; keep demonstration smooth and continuous.

$>$ Never demonstrate on a student's material.

$>$ Work towards one aim.

$>$ Allow time for possible student participation.

\section{Carrying Out A Demonstration}

$>$ Give a good performance. Remember that the trainees learn by your good example.

$>$ Explain each step or process as you proceed. Follow your lesson plan.

$>$ Make sure the trainees see the demonstration from the angle they will perform it themselves.

$>$ Be sure everyone can see and hear. Maintain eye contact.

$>$ Emphasise key points, and if possible prepare before hand ask key questions as you go along and allow trainees to ask questions.

$>$ Observe all safety rules, precautions and procedures; and emphasise them.

$>$ Use proper instructions, aids such as chalkboard, charts, handouts e.t.c. to support your demonstration.

$>$ Provide for trainees participation where possible, during and after demonstration.

$>$ Demonstrate the correct way only. First impressions are important, therefore, make them correct ones.

$>$ Always summarise the steps and emphasise key points again.

\section{After Demonstration}

$>$ Return all items used during demonstration to their storage places.

$>$ Make arrangements to have the trainees practice the skill as soon as possible in a practical class session.

$>$ Observe and analyse trainee(s) performance and correct mistakes.

$>$ Offer reinforcement where necessary.

$>$ Coach weak or slow trainees.

$>$ Check trainee's completed work for accurate performance and record.

$>$. Allow sufficient time interval before demonstrating another operation.

Problem-Based Learning (PBL)

It is a flourishing approach to learning that is extremely useful in promoting critical and analytical thinking, and in addressing the rapid technological changes and dynamic workplace of the 21 st Century. PBL is founded on an unconventional pedagogical model when viewed alongside the conventional didactic one and it offers greater benefits to the quality of student learning (Greening, 1998). This approach to education suggests a strong role for factors such as authenticity, as well as student independence, and is principally associated with the encouragement of deep learning (Sutherland, 2009). In this approach, a range of selected constructive 
problems are designed by the lecturer to address the desired learning outcomes. These problems may be influenced by community and contextual factors. It is assumed that most students already have basic conceptual knowledge. PBL is an approach to learning that incorporates relevance and complexity of thought and it also provides an opportunity for self-assessment and continuous improvement on the part of the students. As in the problem-solving approach described above, students seek out solutions to problems and are able to develop a sense of ownership for their work. This also promotes self-esteem as students acquire important discipline knowledge by their own initiatives and the students take ownership of their education.

Unfortunately, lecturers are often resistant to changing their methodology and this reflects fear, insecurity and ignorance. They prefer to be knowledge-providers and to be seen as experts. In PBL they are neither and now have to handle group dynamics and become anxious but this should not be the case as PBL is a very useful didactic operating strategy. Course content is introduced in the context of real world-of-work problems that students are likely to encounter at some or other time during their careers. The student learns by means of self-directed learning strategies which may be either independent or collaborative or both. Studentgenerated questions are encouraged as lecturers monitor student content knowledge. The problems that are presented for solving must be engaging and interest the students. The students must have reasoning ability which they can support with evidence which is in tandem with the learning objectives of the course. What is important is that no one answer to a problem should be the only correct one.

\section{Conclusion}

Any innovative teaching and learning method is not a quick fix or universal remedy. It cannot replace a traditional teaching methodology in education but rather supports it. However it is clear from the literature, that innovative teaching methods do provide students with greater experience in dealing with the world of work related issues they encounter. Innovative teaching methodologies will lead to a learning society in which the creative and intellectual abilities of students will allow them to meet the goals of transformation and development. Where students claim to experience problems with assessment, the general argument is that the lecturers have not adequately explained what is required of them. Other student problems include excessive workloads and insufficient feedback. Lecturers need to consider these aspects when adopting any methodology. Given the constructivist nature of the PBL approach, there is a larger retention of knowledge and students enjoy their learning experience far more than in traditional approaches-course content is understood more thoroughly. Bauer et al (2008) found that students enjoyed the real world of work issues and teamwork aspect of PBL. They also and felt welcome in the classes and stated that their learning was enhanced as PBL augmented their ability to consider, evaluate, and respect diverse viewpoints. The use of the short-lecture, simulation and roleplaying, and the submission of individual student portfolios, undoubtedly support traditional methodologies and should also be utilised more. Education for the future requires that we explore as many varieties of models and teaching methodologies as possible. We need to remain cognisant of the culturally and other specific needs of our students and must not underestimate the influence of technology such as the internet in promoting quality teaching and learning and in enhancing education in general.

\section{Referances}

[1] Hamilton, A. (2010). Innovative teaching strategies for student-centered learning: Utilizing Honey \& Mumford's Learning Styles.

[2] Damodharan V. S. \&Rengarajan .V (1999). Innovative Methods of Teaching. NationalResearchCouncil, Educational Journal Publication.

[3] Orlich D. C, Harder R. J, Callahan R. C, Gibson H. W (1998). Teaching strategies: a guide to better instruction (5th edition), New York.

[4] Sheppard, L. (2000). The role of assessment in a learning culture. Educational Researcher, 29(7), 4- 14. (C) 2012 Global Journals Inc. (US) Effects of Innovative Teaching Strategies on Students'performance

[5] Steven, M. \& Jennifer, K. (2004). Integrating Scientifically Based and Design Experiment Research.

\footnotetext{
IOSR Journal of Business and Management (IOSR-JBM) is UGC approved Journal with S1. No. 4481, Journal no. 46879.

V. Senthilkumar. "Impact of Innovative Teaching and Learning Methodologies for Higher Educational Institutions with Reference to Trichirappalli District." IOSR Journal of Business and Management (IOSRJBM) 19.7 (2017): 88-92.
} 